\title{
What the American
}

Consumer Really

Thinks of Olive Oil

June 2014 


\section{Introductions}

- The North American Olive Oil Association (NAOOA)

- Trade association of olive oil marketers founded in 1989

- Primary Missions:

- Fair \& Competitive Trade

- Quality Monitoring

- Increase Olive Oil Consumption

- Eryn Balch

Confused Consumer
Experienced Enthusiast

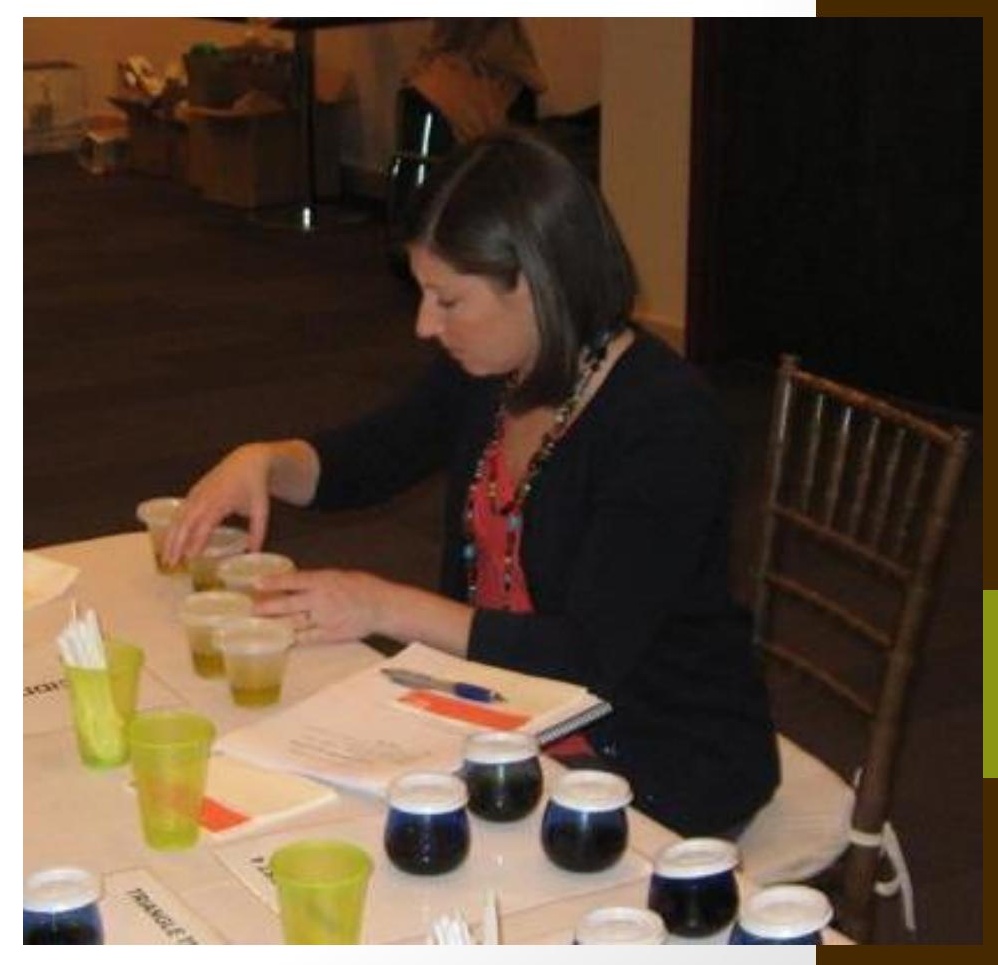




\section{World 00 Consumption per Capita Olive Oil Consumption per Capita}

Approx Liters

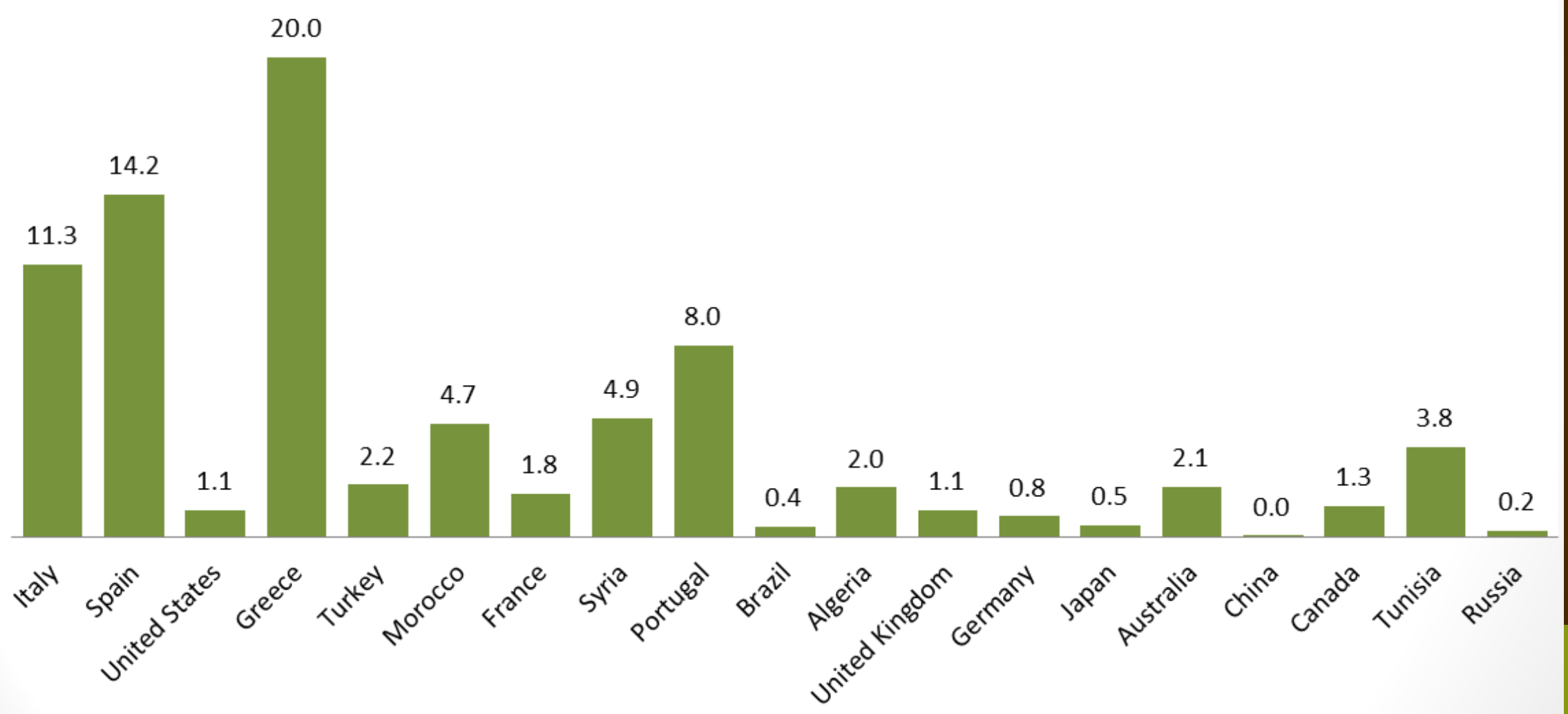




\section{US Retail Pourable Oil by Type}

\section{U.S. Pourable Oil Volume}

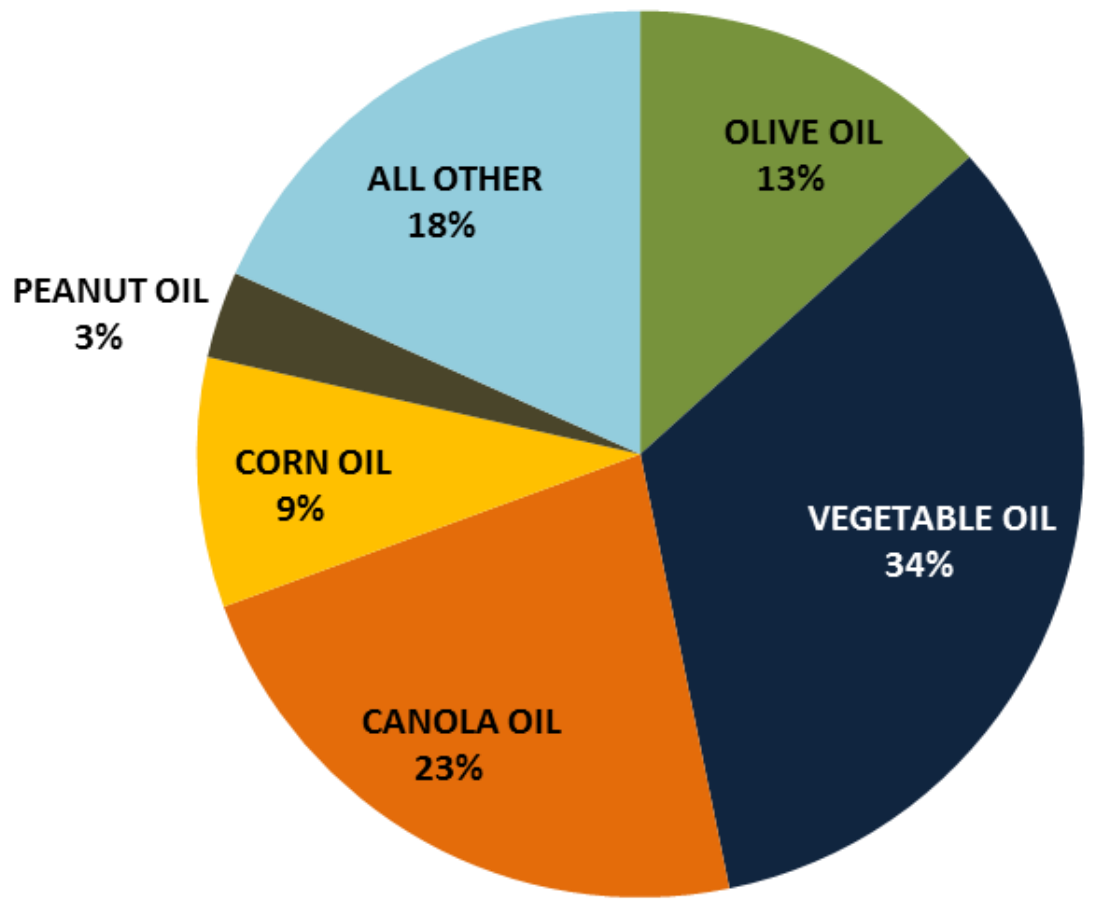

Total Volume Sales: 247.2 Million Gallons Percent Change vs. Year Ago: $+0.5 \%$

\section{U.S. Pourable Oil Value}

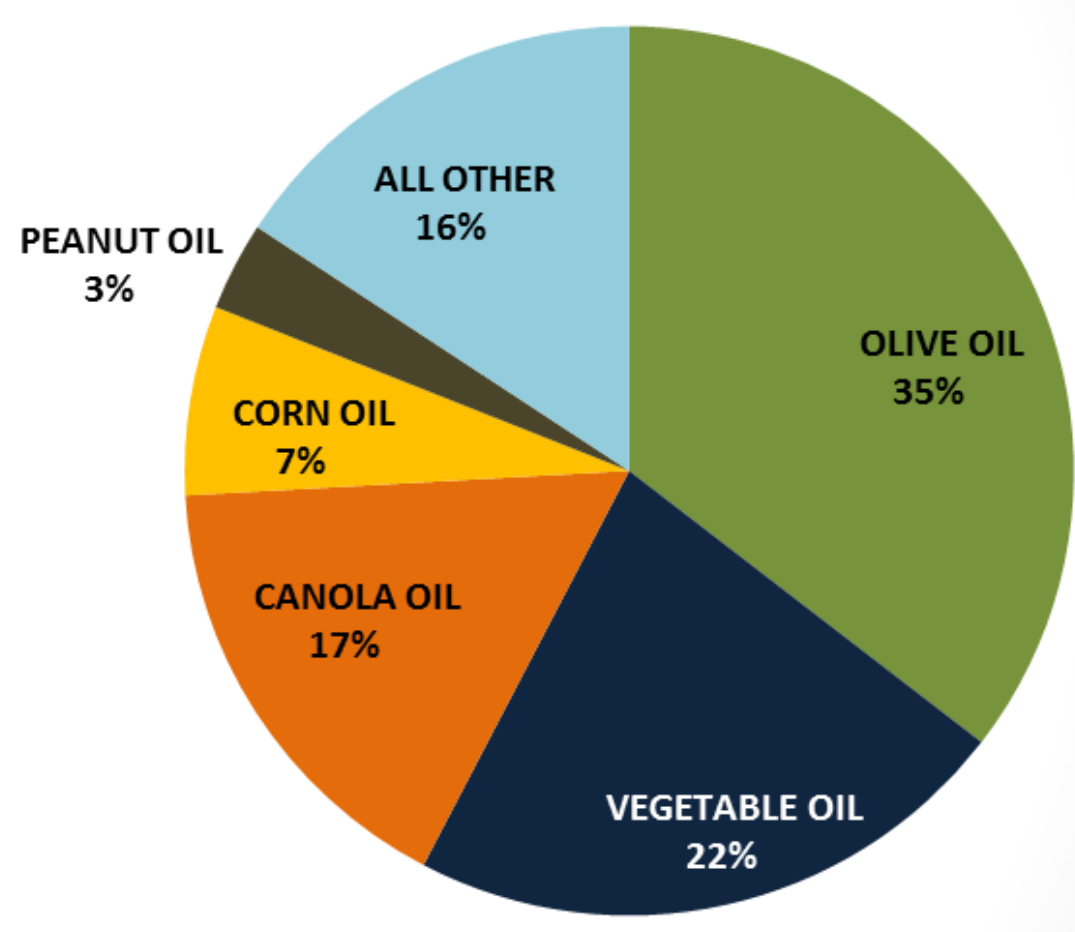

Total Dollar Sales: \$3.03 Billion Percent Change vs. Year Ago: $+1.7 \%$ 


\section{Total US Olive Oil Retail Market}

Current 52 Weeks through May 10, 2014

\begin{tabular}{|r|r|c|c|c|}
\hline & \multicolumn{3}{|c|}{ Current 52 Weeks through May 10, 2014} \\
\hline TOTAL US - XAOC Liters & $\begin{array}{c}\text { Liter \% Chg } \\
\text { Year Ago }\end{array}$ & Dollars & $\begin{array}{c}\text { Dollar \% Chg } \\
\text { Year Ago }\end{array}$ \\
\hline Olive Oil & $123,579,380$ & $-1.9 \%$ & $\$ 1,070,121,261$ & $6.2 \%$ \\
\hline
\end{tabular}

\section{Liter Share by Type}

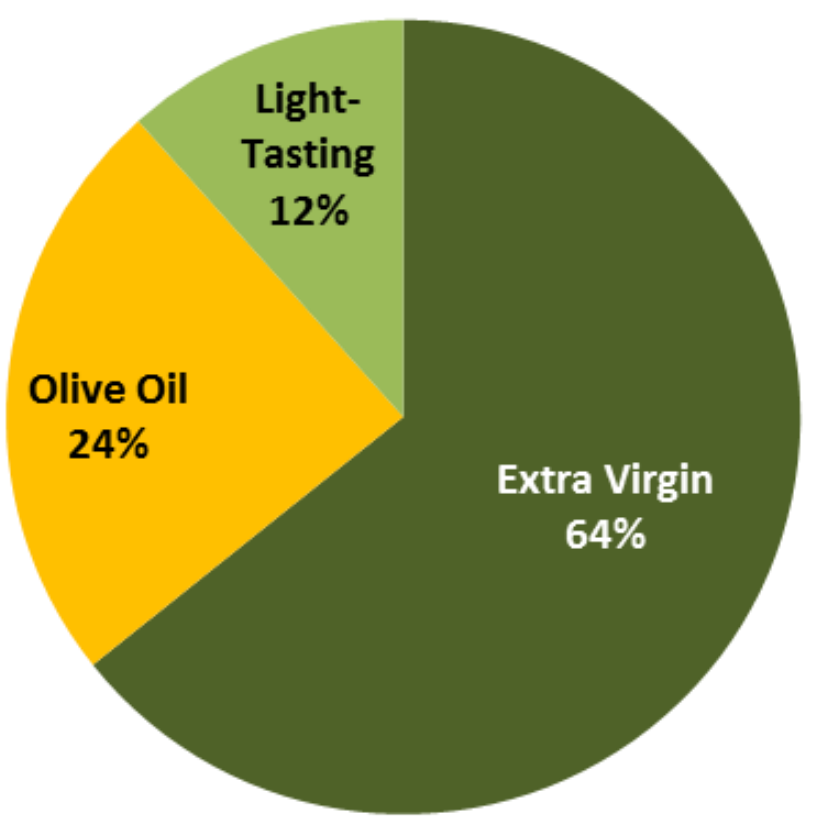

Unit Share by Package Type

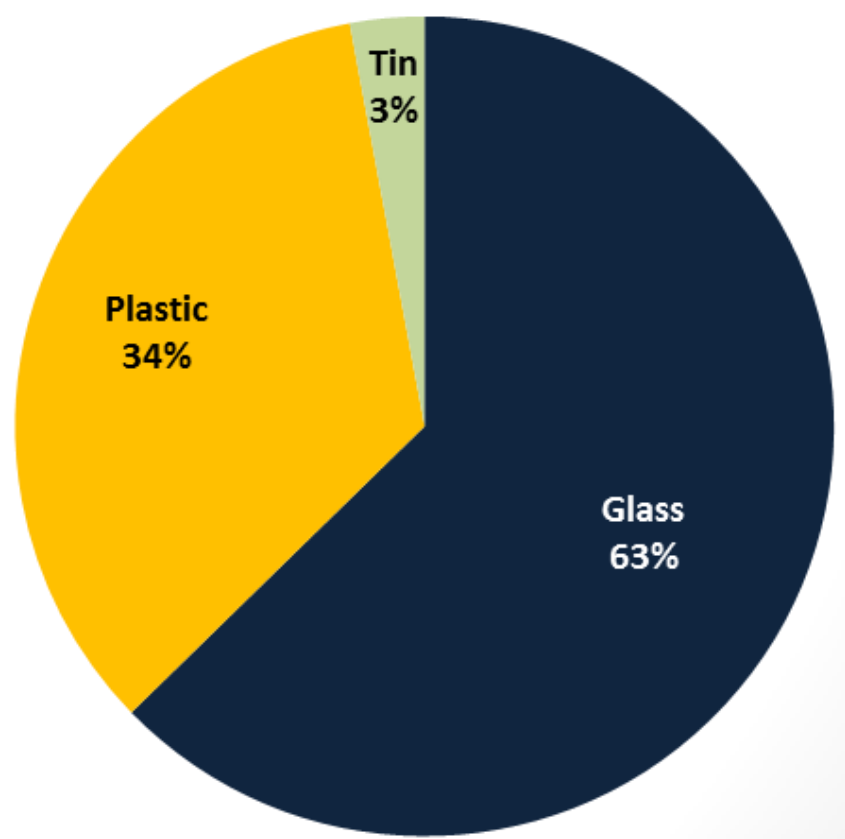




\section{Olive Oil Volume by Region Olive Oil Liters by Region}

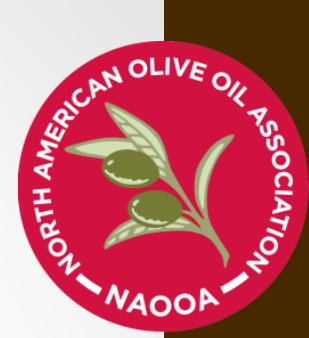

EAST SOUTH CENTRAL

$4 \%$

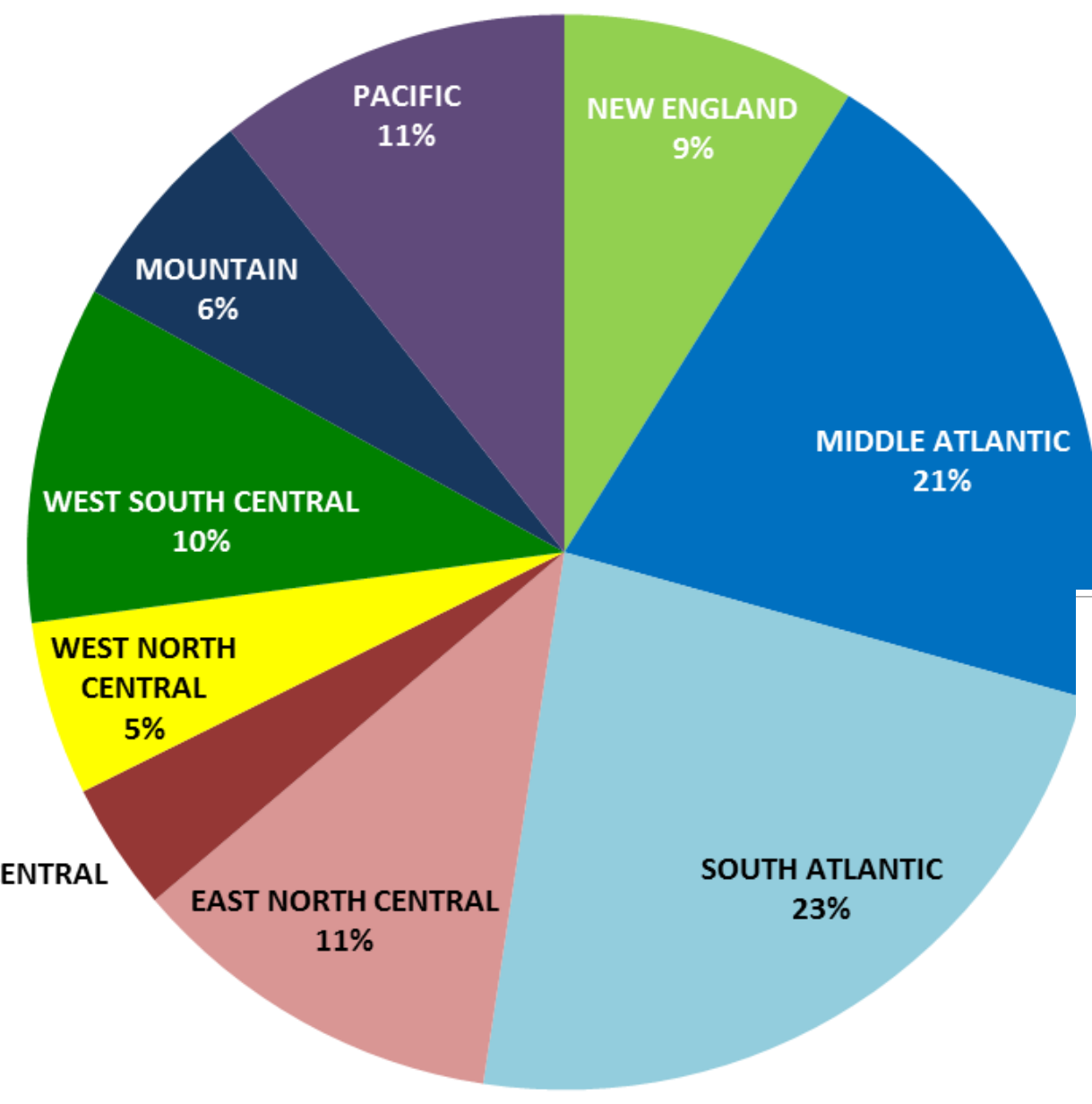

Source: Nielsen 52 Weeks Ending May 10, 2014 (includes Walmart \& Club Stores)

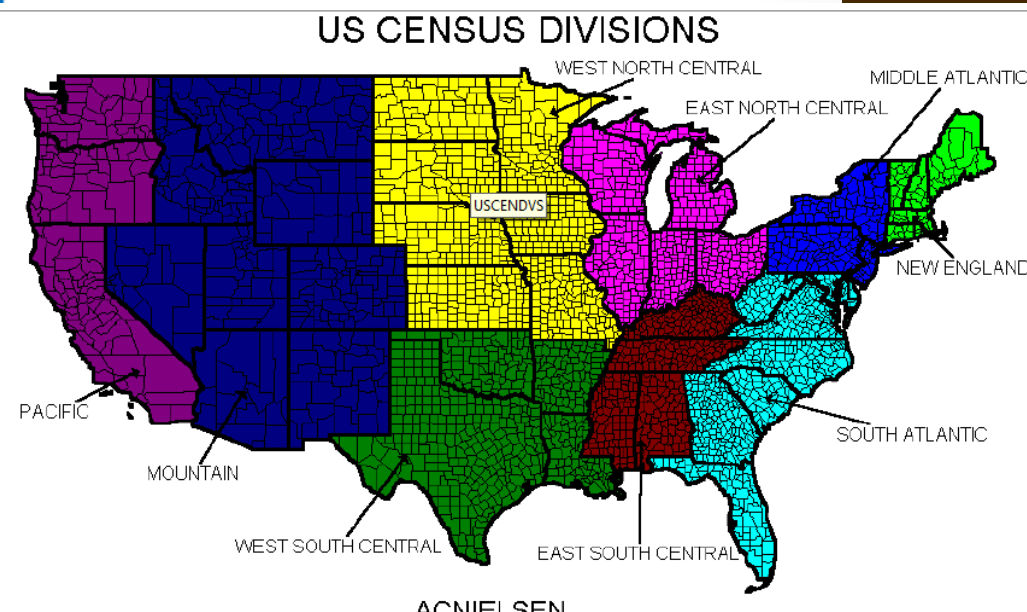

ACNIELSEN 


\section{National Attitude \&}

\section{Usage Study}

$\mathbf{N}=\mathbf{2 , 0 0 2}$ national online survey that covers the nine US Census Regions

February 12-20, 2014 (2) 25 minutes

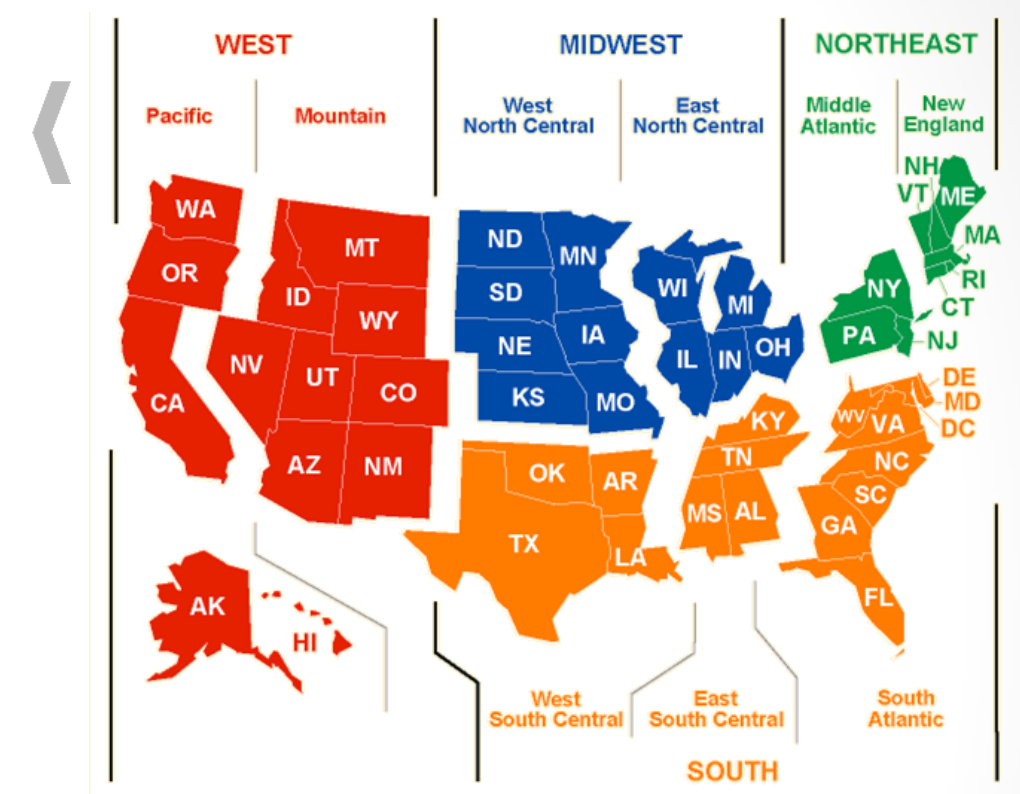

To be eligible for the survey:

of Must have used 00 in past six months

Must be the primary/shared $\mathrm{HH}$ grocery shopper

(iin Must be the primary/shared $\mathrm{HH}$ meal preparer 


\section{Key Insights Reviewed Today}

- Once a consumer becomes an olive oil user, they tend to use it a lot

- Users find olive oil to be very versatile

- Overall trend is towards increased usage
- Choosing an olive oil can be difficult and confusing

- Many myths about olive oil persist

- Education and direction will increase consumption 


\section{More than half of Olive Oil users use it more than any other oil}

\section{Olive Oil Users}

Have Purchased and Used Oil in the Past Six Months

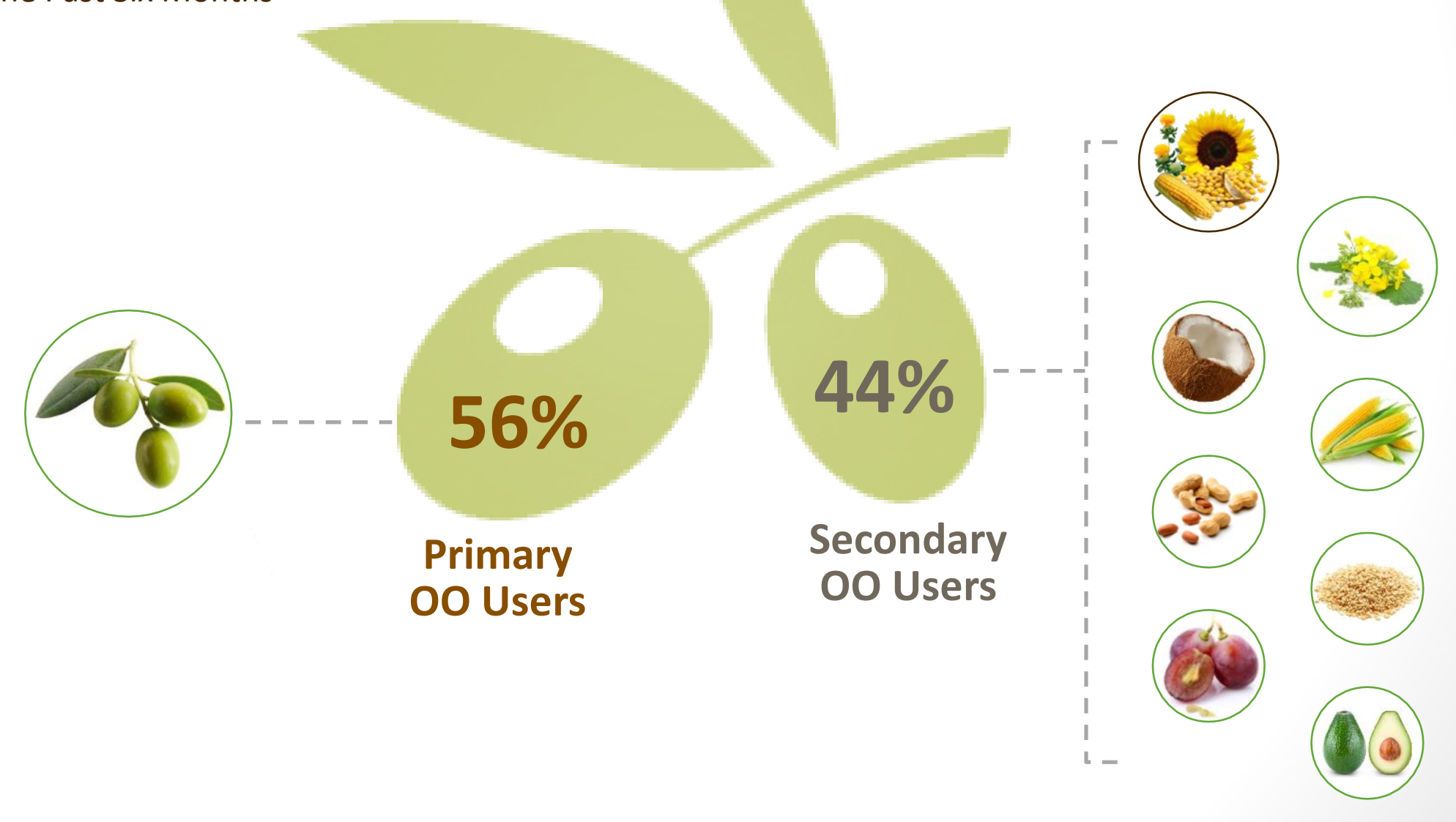




\section{Once they become users, they tend to use Olive Oil a lot}

- Consumers who use Olive Oil tend to use it more than other oils or a close second

- Over half use Olive Oil more than any other oil; the majority of the remainder say they use it second only to vegetable or canola oil

- In fact, $16 \%$ of those using Olive Oil as their primary oil say they ONLY use Olive Oil (or $9 \%$ of all users)

- Over half of these users say they last used Olive Oil in the past day or two. This increases to two-thirds among those that choose Olive Oil as their primary oil

- Three-quarters say they use Olive Oil several times weekly

- Only 7\% say it's been more than two weeks since they last used

- EVOO is by far the type of Olive Oil used most often: three-quarters name EVOO their go-to oil, followed by only $15 \%$ for classic Olive Oil 


\section{Profile of Primary 00 Users}

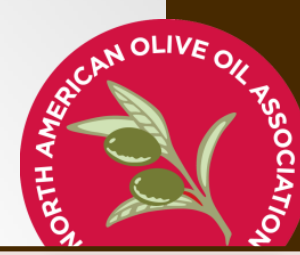

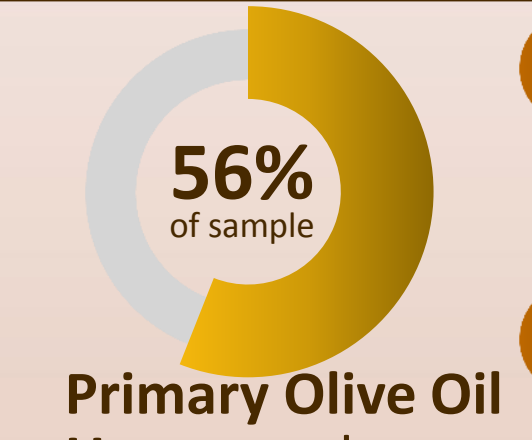
Users are those who use Olive Oil more than any other oil

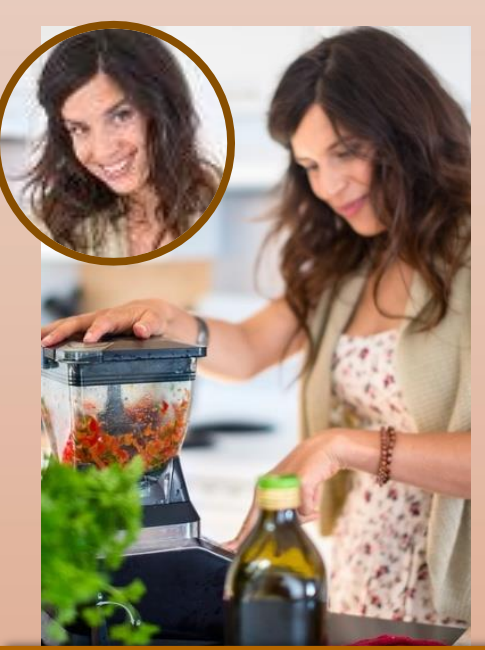

DEMOGRAPHICS

To have completed post graduate study

To be employed full time

To live alone or not have children living in their household To consider themselves white

To have annual household incomes greater than $\$ 50,000$

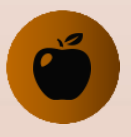

More likely to say their family diet is healthy

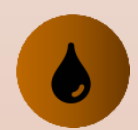

USAGE

Tend to use Extra Virgin Olive Oil for most purposes And use Extra Virgin Olive Oil most often

More likely to cook with Olive Oil across the board

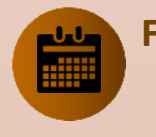

FREQUENCY \& TREND

More likely to have used Olive within the last day or two and to use on a daily basis More likely to say their usage increased a lot in the past year Say they would use more Olive Oil if they cooked at home more More likely to be long term Olive Oil users

More likely to cite health benefits as the reason for starting to use Olive Oil

\section{CHANNELS}

More likely to purchase from a specialty or gourmet food store When buying Olive Oil - More likely to focus on the type of Olive Oil and pay attention to the color of the oil in the bottle

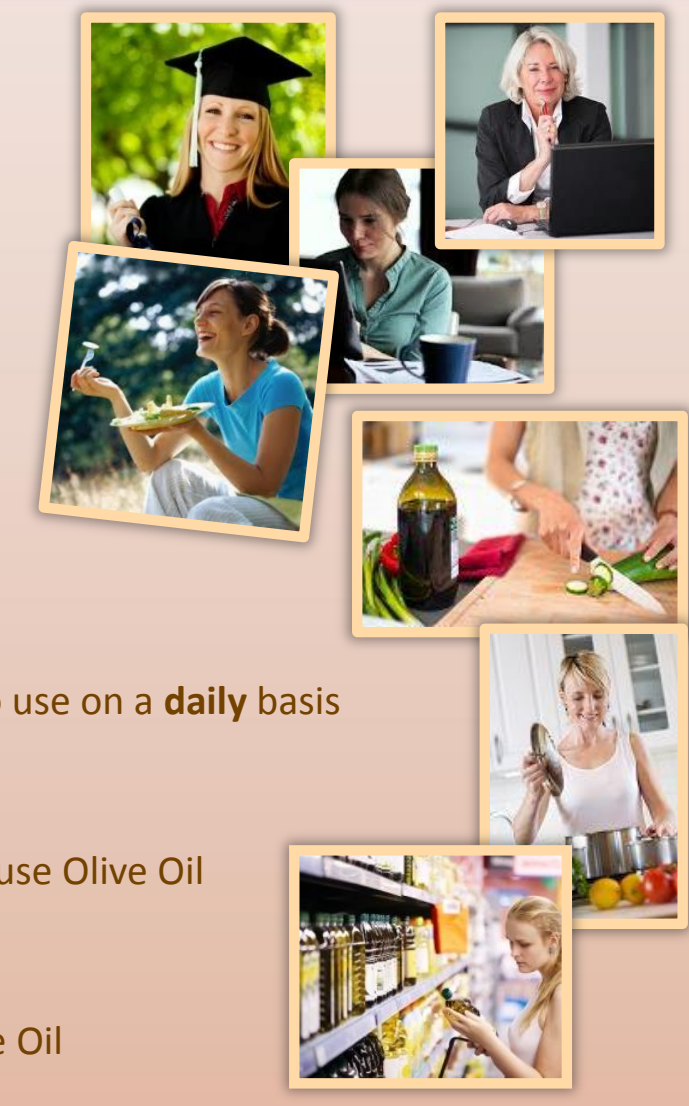

KNOWLEDGE \& UNDERSTANDING

Have greater confidence in their understanding of the health benefits of Olive Oil and how to use as a substitution for butter or other oils in recipes More likely to say "yes, I know" where my olive oil comes from 


\section{Profile of Secondary OO Users}

\section{DEMOGRAPHICS}

To be a high school graduate

To be a homemaker or a student

To not be married

To have children living in their household

To consider themselves non-white

To have annual household incomes less than $\$ 50,000$

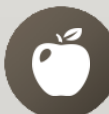

More likely to say their family's diet is average to most Americans

\section{Secondary Olive}

Oil Users are those who use Olive Oil but use another oil more often

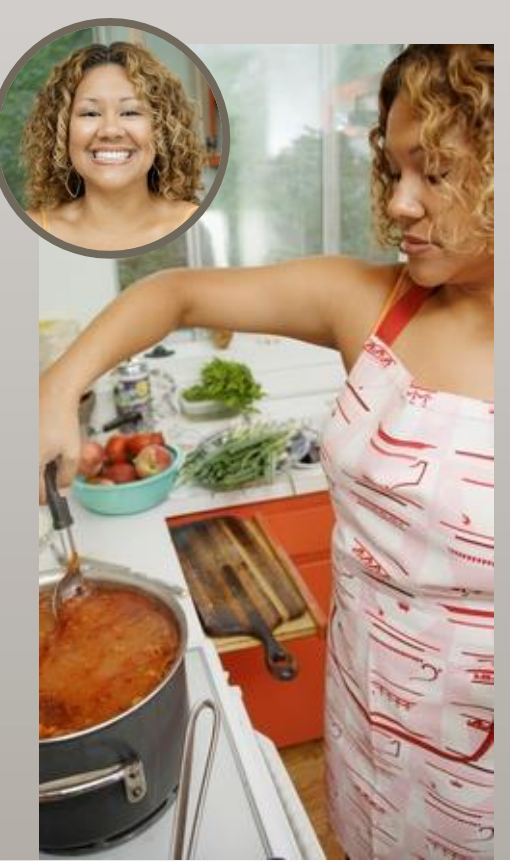

\section{USAGE}

Use vegetable ( $45 \%)$ or canola oil (39\%) most often

More likely to currently use Classic/Regular Olive Oil and to use it most often More likely to have one bottle of Olive Oil in their kitchen

More likely to prefer Olive Oil to taste buttery

\section{FREQUENCY \& TREND}

More likely to have last used Olive Oil a few days ago or a week ago or more More likely to use Olive Oil monthly or less

More likely to say their Olive Oil usage decreased in the past year More likely to say they would use more Olive Oil more often if it were priced more affordably or if their recipes called specifically for Olive Oil More likely to have started using Olive Oil in the last one to three years More likely to say they started using Olive Oil because it was called for in the recipe or it was recommended by friend or family

\section{CHANNELS}

More likely to purchase from a mass retailer

More likely to pay attention to the best by date and

the taste/flavor description on the label when purchasing

\section{KNOWLEDGE \& UNDERSTANDING}

Want more information on how to spot poor quality Olive Oils while shopping and on the difference between grades or types of Olive Oil More likely to say "no, I'm not sure" where my Olive Oil comes from
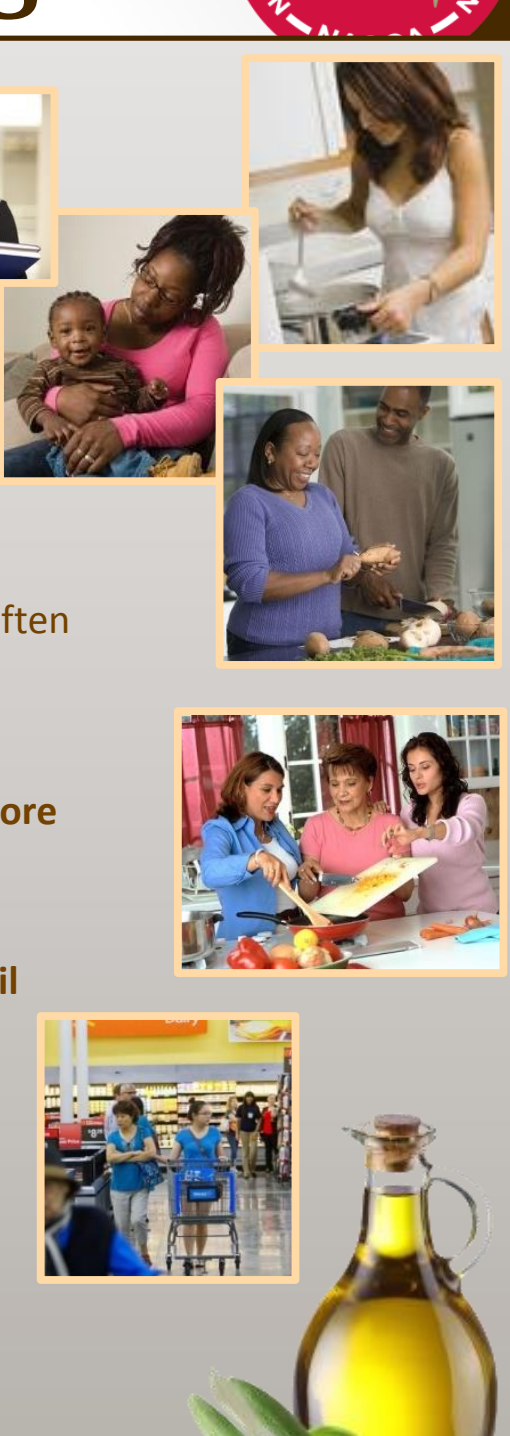


\section{Users find Olive Oil versatile for}

myriad cooking types, foods

- Chicken and vegetables are foods most frequently cooked using Olive Oil, followed by pasta, fish and beef/red meat (all cooked with $\mathrm{OO}$ by more than half of users)

- Sautéing and stir-frying are the cooking types where Olive Oil is used most, but many uses are cited

- Flavoring in dressings, seasoning and marinating are also primary uses

- Olive Oil is least used for deep frying and baking

- Extra Virgin Olive Oil is used more than other types of Olive Oil for all types of cooking

- Secondary OO users do tend to use classic more often than do Primary OO users, but EVOO is still used more than classic Olive Oil

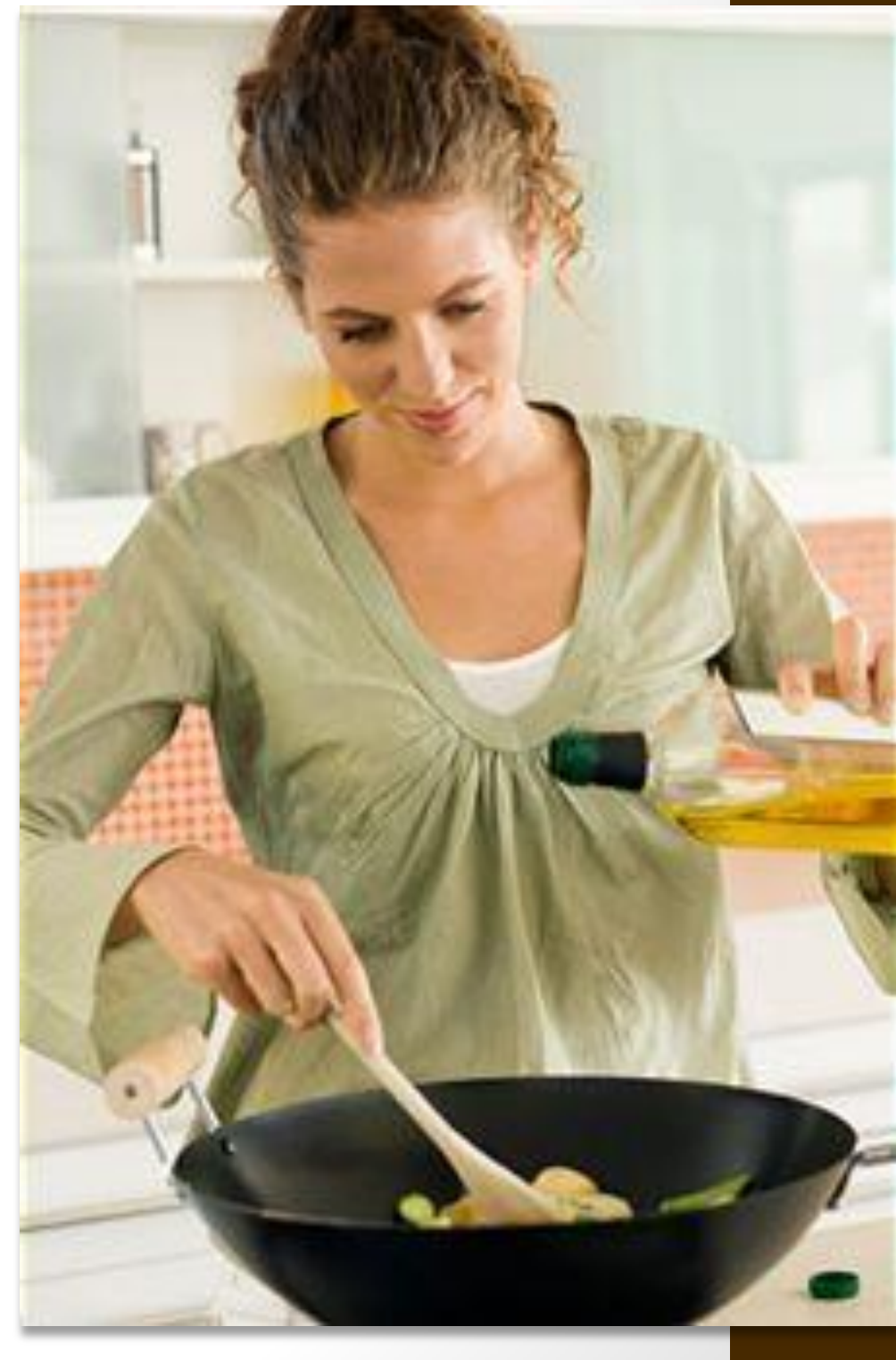




\section{Trend is toward increased use;}

\section{new consumers joining}

- Trend is toward greater frequency of usage of Olive Oil: over half say their usage of Olive Oil has increased in the past year

- Primary reasons cited for increased usage is that Olive Oil is healthy and is good for the diet - and many say it's more natural than alternative oils

- Others say they have been cooking at home more often and they prefer the taste of Olive Oil in their cooking

- Very few (2\%) cited any decrease in usage. Those that did said cost played a role in that decrease or that they were decreasing usage of any oil in their diet

- One-third of current users started using Olive Oil just in the last three years

- Of course, age plays a role here: younger users tend to be newer to using Olive Oil than older users. But even so, we see increases in "non-traditional" areas for Olive Oil with non-whites, and those living in the Midwest and South

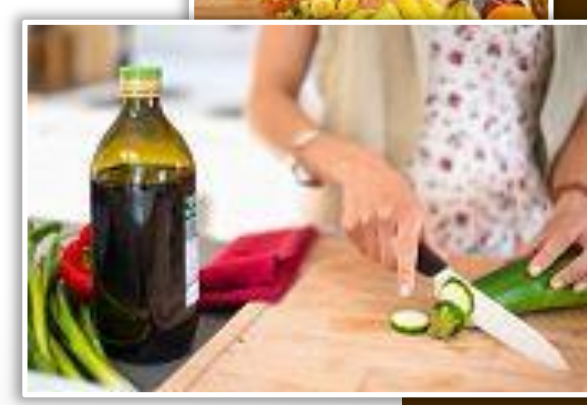




\section{Beyond health, primary users more varied in}

reasons; secondary influenced by friends \& med

\section{Primary 00 Users}

\section{recipe called for it}

substitute for other oils

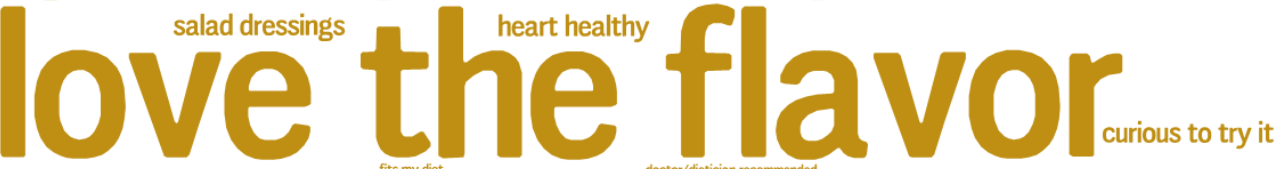

all kinds of usesfriend or family recommendation

or Italian/Greek/Mediterranean dishes
prew UP of my heritage taught to cook with it substitute for butter/margarine

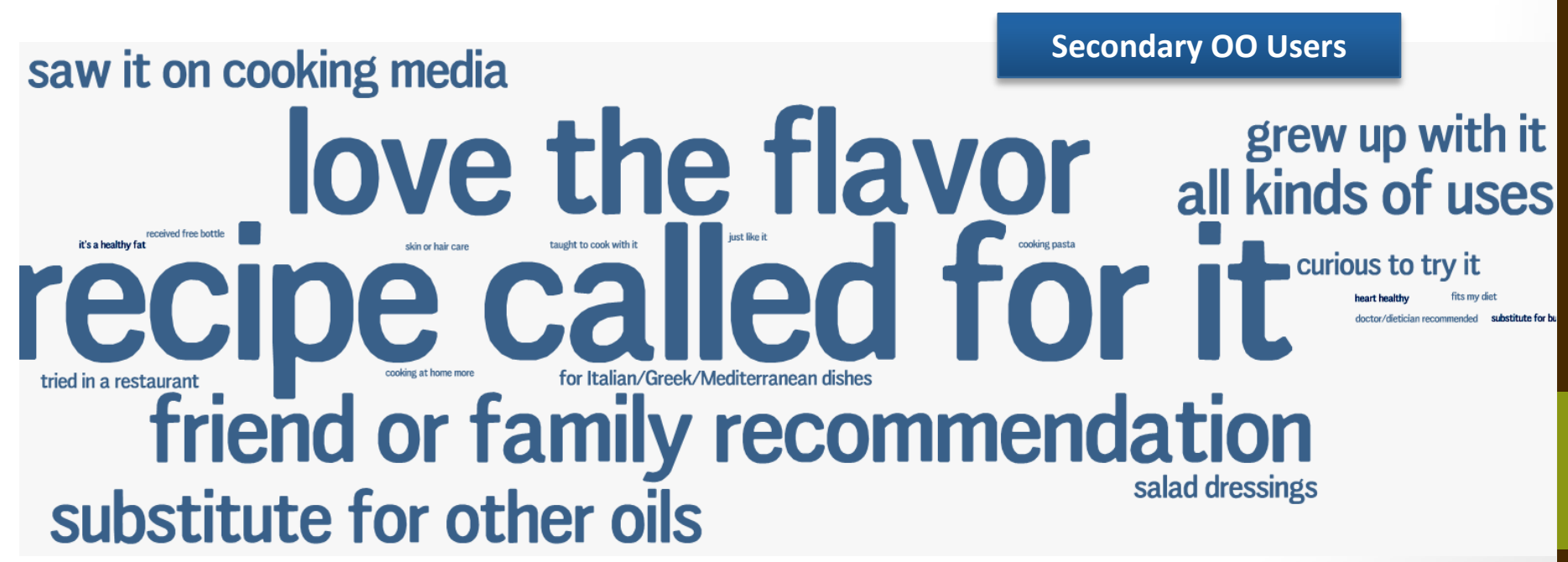

Base: Primary OO Users $(n=1,115)$, Secondary OO Users ( $n=887$ )

Q20. Thinking back to when you first started using olive oil, what were the main reasons you started using olive oil in the first place? 


\section{Choosing an Olive Oil can be difficult and confusing}

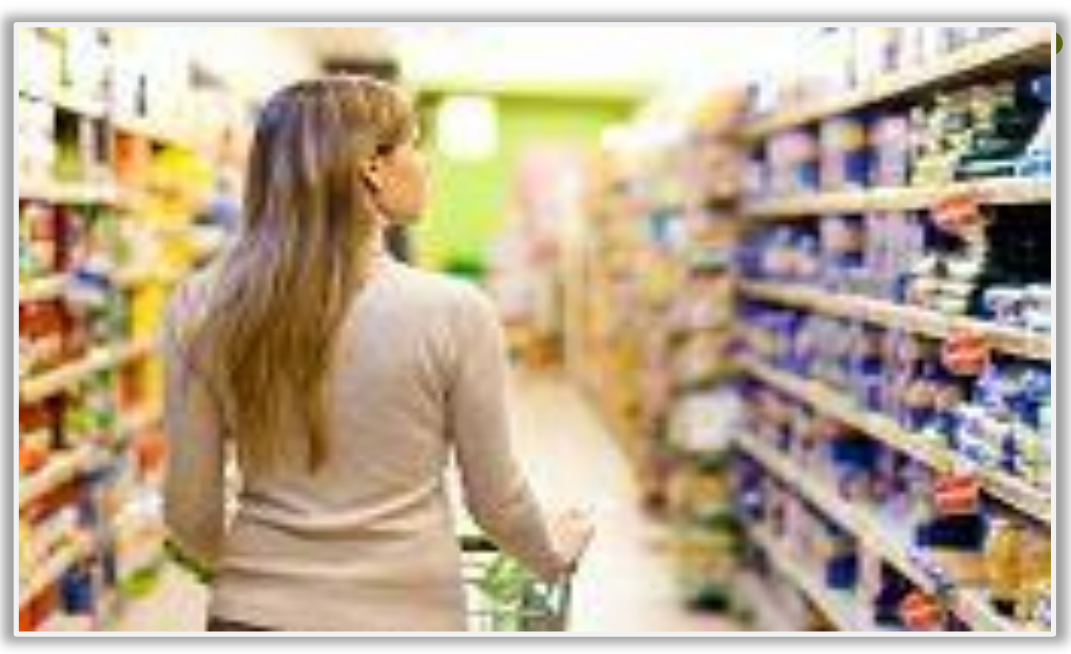

More than half of Olive Oil users agree that choosing an olive oil is confusing because they aren't sure what's important

- In fact, only $25 \%$ say they are very "knowledgeable" about OO

- Olive Oil users want more information on how to choose and how to use olive oil, as well as the differences between grades (especially those who are Secondary OO users)

- Certification can be an assurance of quality to consumers, but beyond "USDA" certification, none of the other organizations carried as much cache 


\section{Many Olive Oil Myths Persist}

- The color of olive oil False is related to its quality
- Like wine, olive oil gets better with age

- Only $24 \%$ know this is false

- Only 6\% know this is false

- Light-tasting olive oil has fewer calories than other olive oils

- Only $16 \%$ of users know this is false
- Extra virgin olive oil False is for cold or raw use only
Only $30 \%$ know this is false 


\section{Use can be encouraged with education, direction}

- Most users say they are faithful to recipes and try to use the oil that's specified. The majority say they would use Olive Oil more often if the recipes they use called for it by name

- And 7 in 10 say they would buy a type of Olive Oil they didn't have if the recipe called for it

- Many say they would increase their use if they understood better how to substitute Olive Oil for other oils/butter

Health is a major factor in Olive Oil use; it's the number one reason cited for initial use of Olive Oil

- The vast majority of consumers agree that Olive Oil is healthier than other oils and that it can be used in place of less healthy oils or butter 


\section{Mobile Education Results}

This is a sponsored message

- Average mobile CTR: $0.35 \%$

- Olive Oil

Education CTR: average $5.57 \%$

- Of 8 Quizzes, CTRs ranged from $3.84 \%$

$-7.81 \%$

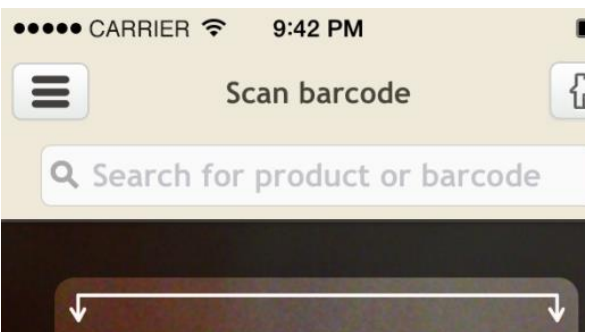

- Answer: FALSE!

Contrary to popular belief, the color of an extra virgin olive oil is not an indicator of its quality or flavor. The color of an EVOO

depends upon many factors, such as the

olive variety, growing conditions

(temperature, water, etc) and fruit maturity at

harvest time. Good quality extra virgin olive oils may range in color from yellow to green.

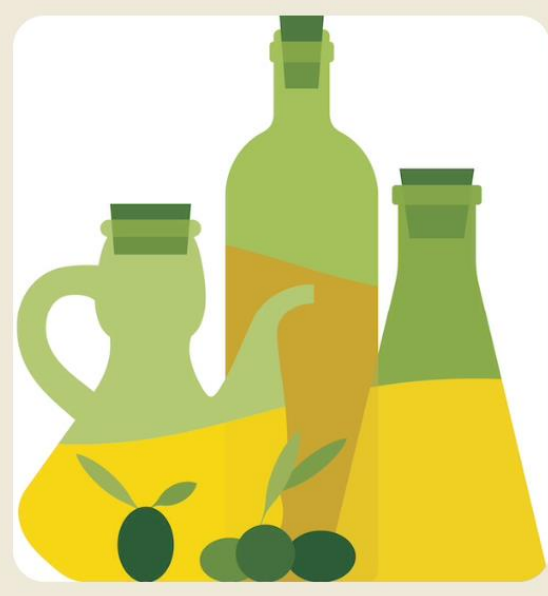

For more information, please visit the North True or False: Extra Virgin Olive Oil should look very green.

2 False
(1) True

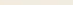

American Olive Oil Association

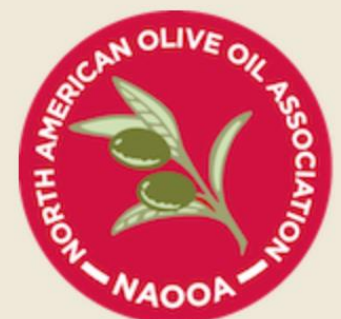




\section{Takeaways}

- Even current olive oil users are "hungry" for information

- Debunk Myths

- Color/Quality, Can Cook with Olive Oils

- Encourage substitution

- Any oil cup for cup

- Butter to Olive Oil conversion chart

- Explain the grades

- Health, flavor, usage

- Extra Virgin Olive Oil

- Healthiest, most flavorful, variable smoke point

- Olive Oil

- Healthful, mild flavor, more consistent smoke point

- Handling \& Storage

- Doesn't last forever

- Avoid heat, light \& air 

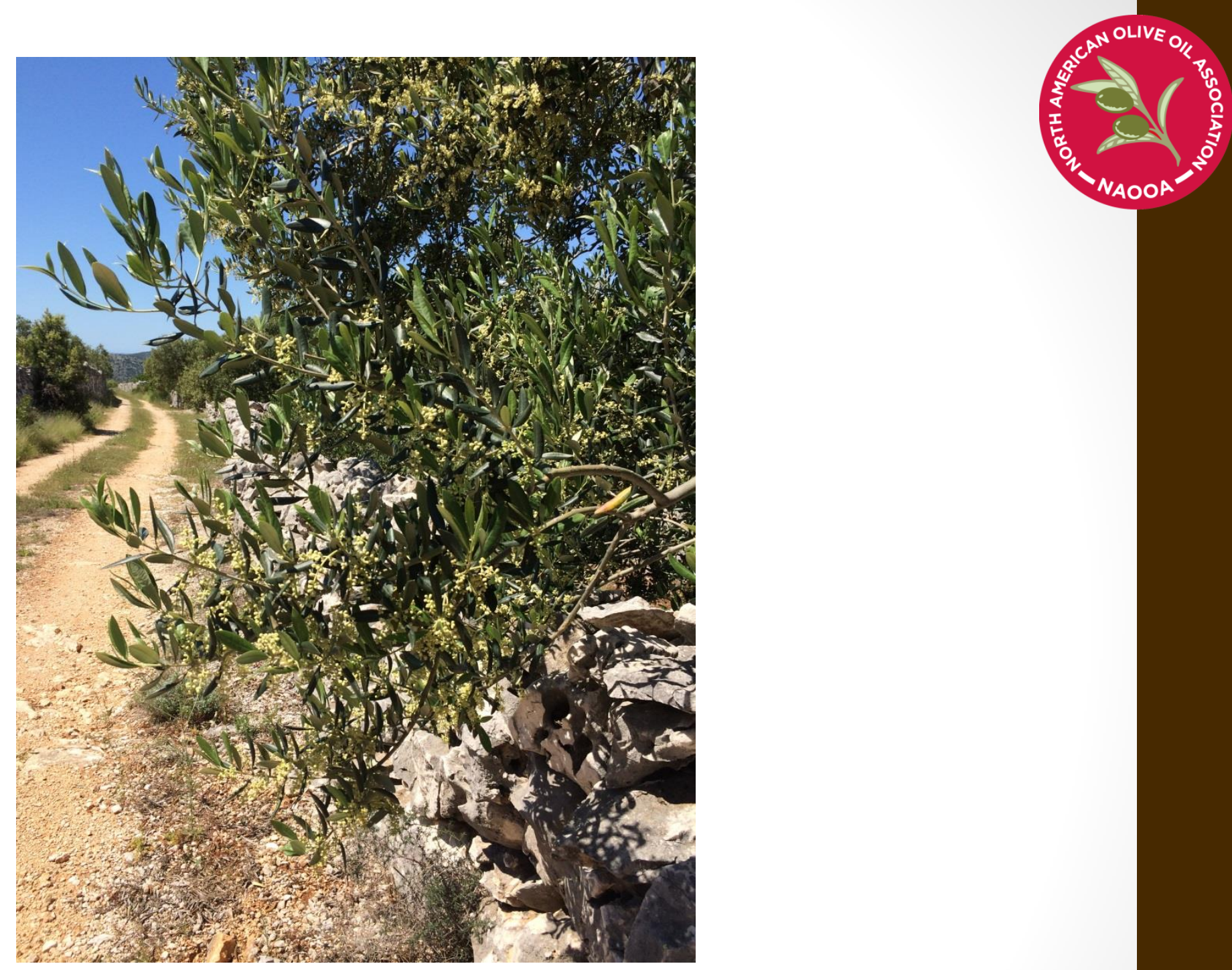

\section{Thank You}

www.AboutOliveOil.org 